\title{
Preliminary Study on the Fabrication of Particulate Fuel through Pressureless Sintering Process
}

\author{
Jong-Hwan Kim, Jung-Won Lee, Ki-Hwan Kim, and Chan-Bock Lee \\ Next Generation Fuel Division, Korea Atomic Energy Research Institute, Daejeon 305-353, Republic of Korea \\ Correspondence should be addressed to Jong-Hwan Kim; jhk9@kaeri.re.kr
}

Received 20 November 2015; Accepted 4 February 2016

Academic Editor: Leon Cizelj

Copyright (C) 2016 Jong-Hwan Kim et al. This is an open access article distributed under the Creative Commons Attribution License, which permits unrestricted use, distribution, and reproduction in any medium, provided the original work is properly cited.

\begin{abstract}
U-10wt\%Zr spherical particles for use as particulate fuel were prepared by centrifugal atomization and subjected to pressureless sintering, which is one of the simplest powder processing techniques. At sintering temperature of $1100^{\circ} \mathrm{C}$ for 30 or $60 \mathrm{~min}$, all samples ranging from +50 to -325 mesh showed no apparent bonding between the particles. However, at $1150^{\circ} \mathrm{C}(80 \mathrm{~min})$, all samples formed a bulk body and the microstructures showed apparent sintering stages. Particularly, sample B (50-70 mesh) and sample C (70-100 mesh) showed pore characteristics suitable for a particulate fuel. The results suggest that pressureless sinterability for U-10Zr particulate fuel can be improved by adding small-size ( -325 mesh) particles.
\end{abstract}

\section{Introduction}

Fast reactors are an attractive energy source which manages nuclear waste by closing the fuel cycle, thus making the best use of limited nuclear fuel resources [1-3]. Therefore, sodium-cooled fast reactors (SFRs) have been developed in combination with the pyroelectrochemical processing of spent fuel at the Korea Atomic Energy Research Institute (KAERI) of Korea.

Currently, there are two kinds of promising fuels for fast reactors under consideration. One is metal fuel and the other is mixed oxide (MOX) fuel. Metal fuel features high thermal conductivity, a high density of fissile and fertile materials, a negative reactivity factor, and an increase in the passive safety of fast reactors [4-8]. The disadvantages of metal fuel are its lower processability, fuel-cladding interaction, large swelling at high burn-up, and the needed availability of sodium in the fuel-cladding gap. MOX fuel features high irradiation resistance and a more mastered technology $[9,10]$. However, MOX fuel has disadvantages such as low thermal conductivity, high operating central temperature, relatively low uranium content, and low serviceability under transients.

Particulate fuel is one of the innovative fuel forms for fast reactors, combining the favorable features of both metal fuel and MOX fuel [11-13]. It is fabricated by introducing fuel alloy particles directly into the fuel cladding without a mold. This not only promises major savings on mechanical devices, such as grinding machines and presses, but also offers an almost dustless operation. This simple and environmentally friendly production process results in even greater advantages when treating spent fuel, which includes minor actinide. Such alloys are highly radioactive and should be treated in facilities equipped with remote handling devices.

The low melting temperature of metal fuels such as pure $\mathrm{U}, \mathrm{Pu}$, and $\mathrm{U}-\mathrm{Pu}$ alloys makes them unsuitable for hightemperature applications because of the dangers associated with molten elements penetrating the cladding. The addition of certain high-melting-temperature elements such as $\mathrm{Cr}$, Mo, $\mathrm{Ti}$, and $\mathrm{Zr}$ has therefore been investigated to boost the liquidus temperature and enhance the thermal and mechanical stability of the alloy system. The excellent corrosion resistance and mechanical stability during the cycling of U-Zr-based alloys make them promising fuels for fast reactors. Moreover, $\mathrm{Zr}$ metal has a low thermal-neutron cross section and is unique in suppressing interdiffusion between the nuclear fuel and the stainless steel cladding. These favorable properties have led to the development of U-Zr fuel systems for SFRs [14].

Pressureless sintering is a more affordable manufacturing technology than alternative powder processing techniques such as hot isostatic pressing (HIP), spark plasma sintering 


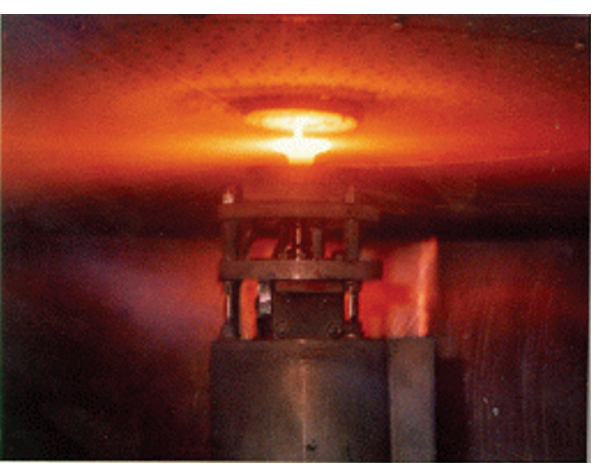

(a)

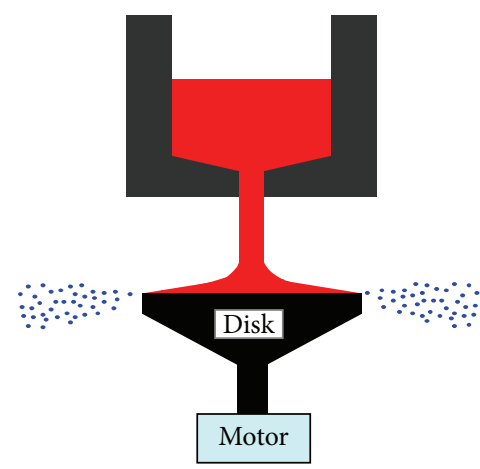

(b)

Figure 1: (a) Centrifugal atomization process and (b) schematic drawing of equipment.

(SPS), and reactive hot pressing. Because it does not involve any preconditioning of the materials, the time, cost, and materials waste can be reduced $[15,16]$. Furthermore, pressureless sintering does not typically remove all of the pores or pore structures during consolidation, which is beneficial in a reactor fuel, because they allow fission products developed during irradiation to travel easily to the plenum. This simple fabrication procedure offers greater advantages during mass production in hot-cell facilities.

Particulate fuel concepts have been proposed and tested at several experimental fast reactor systems [17]. However, much less work has been reported for particulate fuel development. In this study, a U-10wt\%Zr alloy, a proposed metal fuel for an SFR, was used for the fabrication of particulate fuel. The U-10wt $\% \mathrm{Zr}$ alloy was fabricated in the form of spherical particles by a centrifugal atomization process developed at Korea Atomic Energy Research Institute (KAERI) of Korea. The prepared particles were loaded into a surrogate tube cladding according to its size, and then pressureless sintering behaviors were investigated.

\section{Experimental}

Figure 1 shows the centrifugal atomization process (Figure 1(a)) and a schematic of the equipment (Figure 1(b)) used in this experiment. Centrifugal atomization involves melting, atomizing, and collecting. $U$ and $\mathrm{Zr}$ raw materials were heated to a temperature approximately $200 \mathrm{~K}$ higher than the melting point, $1650 \mathrm{~K}$, of the alloy [18], and the molten metal was fed through a small nozzle onto a rotating disk. The alloy-melt droplets, which formed from the melt by centrifugal force, were spread from the disk toward the atomizing chamber wall.

The fabricated particles were classified by sieve analysis and loaded into the quartz mold according to size. The quartz mold, which had a diameter of approximately $8 \mathrm{~mm}$, which is similar to the diameter of the cladding, was coated with $\mathrm{Y}_{2} \mathrm{O}_{3}$ to prevent interactions with the $\mathrm{U}-\mathrm{Zr}$ alloy at elevated temperatures. The molds packed with particles were set in the graphite crucible. The interfaces between the molds and the graphite were also coated with $\mathrm{Y}_{2} \mathrm{O}_{3}$ to prevent interactions during sintering and to allow for easy separation after sintering.
TABLE 1: Sintering conditions performed in this study for $\mathrm{U}-10 \mathrm{Zr}$ particulate metal fuel.

\begin{tabular}{ll}
\hline Characteristics & U-10wt\%Zr alloy \\
Particle shape & Sphere \\
Particle size $(\mathrm{mesh})$ & $+50 \sim-325$ \\
$\begin{array}{l}\text { Sintering temperature }\left({ }^{\circ} \mathrm{C}\right) \\
{[\text { sintering time }(\mathrm{min})]}\end{array}$ & $1100[(30,60)], 1150(80)$ \\
Heating rate $\left({ }^{\circ} \mathrm{C} / \mathrm{min}\right)$ & 2 \\
Sintering atmosphere & Vacuum $\left(<10^{-4}\right.$ Torr $)$ \\
\hline
\end{tabular}

Table 1 shows the sintering conditions performed in this study. Because they are important sintering factors affecting the final densification and microstructure, including pore size and shape, the sintering temperature, sintering time, sintering atmosphere, and heating rate were controlled. Since atmospheric gas could hinder the densification, sintering was conducted under high vacuum $\left(<10^{-4}\right.$ Torr $)$ conditions in this experiment and the heating rate was fixed at $2^{\circ} \mathrm{C} / \mathrm{min}$.

The chemical compositions of the atomized particles and other impurities were assessed by means of inductively coupled plasma atomic emission spectrometry (ICP-AES) and elemental analysis (EA). The sintered samples were cross-sectioned using a slow-speed diamond cut-off wheel and polished using standard techniques. The morphologies of the prepared particles and the microstructures of the sintered samples were examined using an optical microscope (Olympus GX51) and a scanning electron microscope (SEM; JEOL JSM-5800) equipped with X-ray energy dispersive spectroscopy (EDS). Image analysis techniques (iSolution DT image analyzer) were used to quantify the porosity from the cross sections of the sintered samples.

\section{Results and Discussion}

The U-10Zr alloy particles prepared by centrifugal atomization are shown in Figure 2. Figure 2(a) shows the threedimensional (3D) morphology and Figure 2(b) shows a crosssectional view. Most of the particles have a smooth surface and a near-perfect spherical shape, with few attached satellites. The sized particles used in this study ranged from +50 


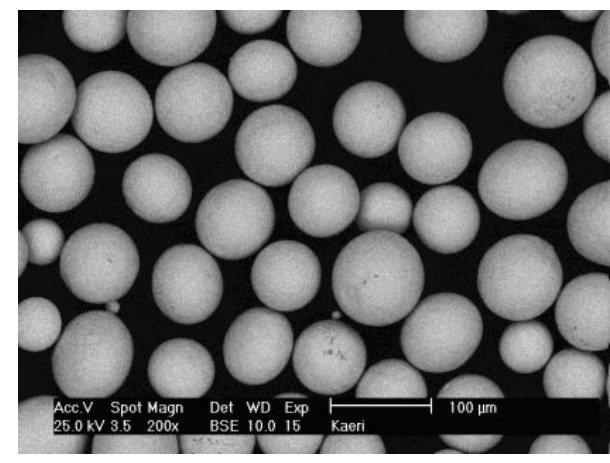

(a)

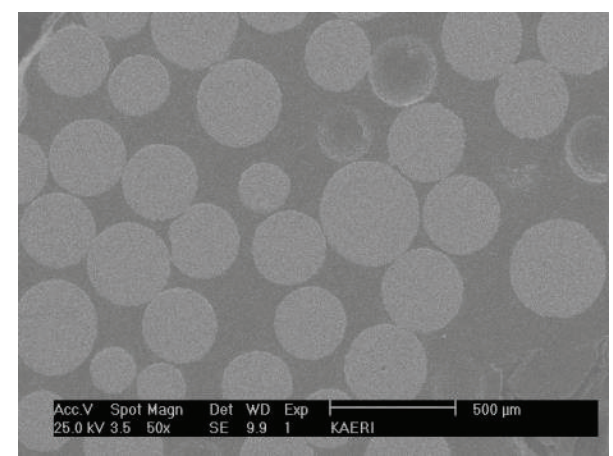

(b)

FIGURE 2: (a) 3D morphology of centrifugal atomized particles and (b) cross section view.

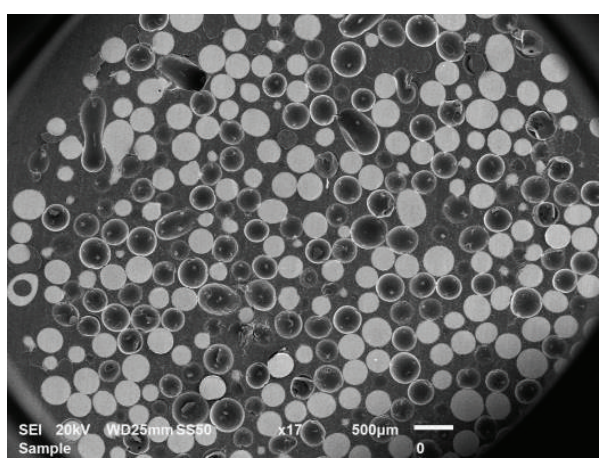

(a)

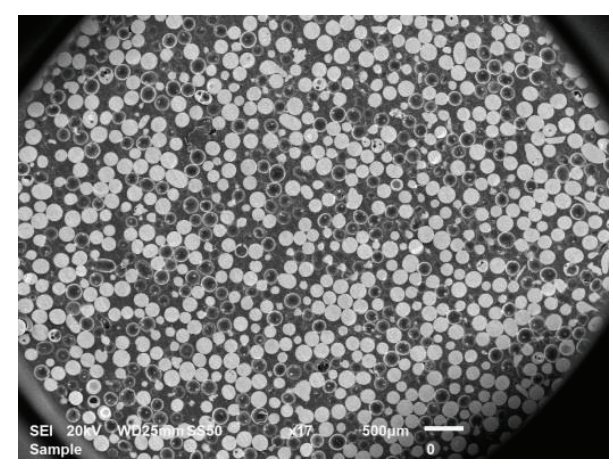

(b)

Figure 3: Particles loaded to the quartz mold: (a) coarse particles in sample A and (b) fine particles in sample D.

TABLE 2: Particle size distributions of sized granules.

\begin{tabular}{lccccc}
\hline Samples & A & B & C & D & E \\
\hline Particle size $($ mesh) & +50 & $50 \sim 70$ & $70 \sim 100$ & $100 \sim 170$ & -325 \\
\hline
\end{tabular}

TABLE 3: Chemical composition of U-10Zr alloy particles by ICPAES and EA method.

\begin{tabular}{lcccccccc}
\hline $\begin{array}{l}\text { Nominal } \\
\text { alloy }\end{array}$ & \multicolumn{2}{c}{ Composition wt\% $\left({ }^{*} \mathrm{ppm}\right)$} & $\mathrm{C}^{*}$ & $\mathrm{H}^{*}$ & $\mathrm{O}^{*}$ & $\mathrm{~N}^{*}$ \\
\hline $\mathrm{U}-10 \mathrm{Zr}$ & 89.7 & $\mathrm{Zr}$ & $\mathrm{Si}$ & & & & \\
\hline
\end{tabular}

The elements with superscripted “*” mark have different unit "ppm" as indicated beside the unit "wt\%."

mesh to -325 mesh and particle size distributions are shown in Table 2. From the results of the chemical composition analysis, the contents of $U$ and $\mathrm{Zr}$ are within $1 \%$ of the target composition and the total impurities of carbon, hydrogen, nitrogen, and oxygen are less than 2000 ppm (Table 3).

The positions of the loaded particle's neighbors and the internal structures of the approximating particles in the quartz mold are important in the evolution of a structure during sintering. Figure 3 shows the initial packing state of the loaded particles. Figure 3(a) shows sample A with coarse particles (+50 mesh) and Figure 3(b) shows sample D with fine particles (100-170 mesh). It can be observed that particles are in contact with their neighbors and that all contacts among neighboring particles constitute a complex contact network. Pores, or holes, are formed between spherical particles, and the shapes and sizes of the pores are dependent on the arrangement of the particles. The packing density of randomly loaded particles for sample A was approximately $9.6 \mathrm{~g} / \mathrm{cm}^{3}$, and the packing density increased as the loaded particle size decreased, such that the particle porosity and the interstices between the particles were regarded as empty space.

Microscopically, sintering minimizes the total sum of system energies such as the surface energy and the grain boundary energy. Macroscopically, sintering could be described as densification resulting from an increase in bulk density with decreasing pore volume [19]. In that sense, the sintering processes can be described by analyzing the microscopic evolution of the arranged particles. At a sintering temperature of $1000^{\circ} \mathrm{C}$ for $30 \mathrm{~min}$, all samples showed no apparent bonding between the particles, suggesting that these sintering conditions were not suitable to produce any measurable densification. The sintered bodies also broke easily into granules. Therefore, the results of the microstructure examination of these samples are not shown here.

The sinterability at $1100^{\circ} \mathrm{C}$ for $1 \mathrm{~h}$ also showed no significant difference except for the sample having fine particles (-325 mesh), which showed some sintering progress. The results of the microstructure examination conducted on 


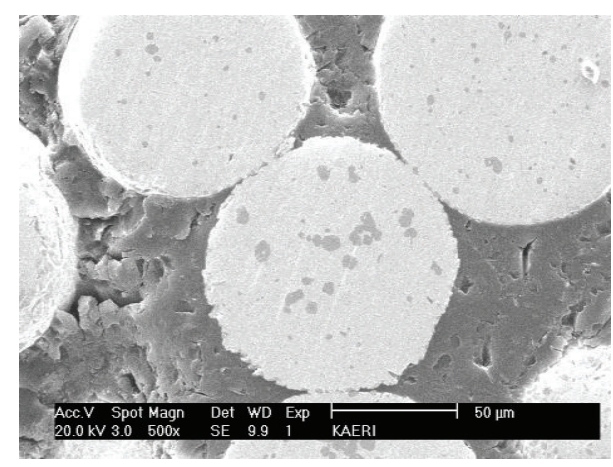

(a)

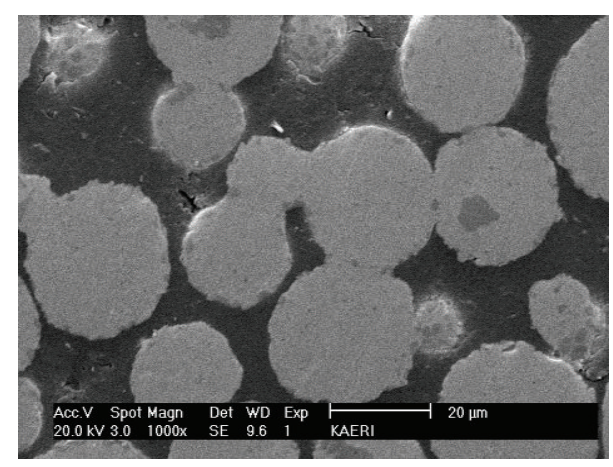

(b)

Figure 4: Scanning electron micrographs of U-10wt\%Zr alloy particles after sintering at $1100^{\circ} \mathrm{C}$ for $1 \mathrm{~h}$ : (a) sample C (70 100 mesh) and (b) sample E (-325 mesh).

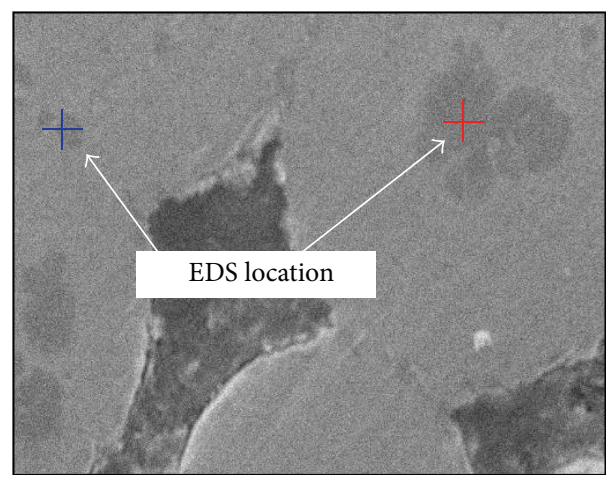

(a)

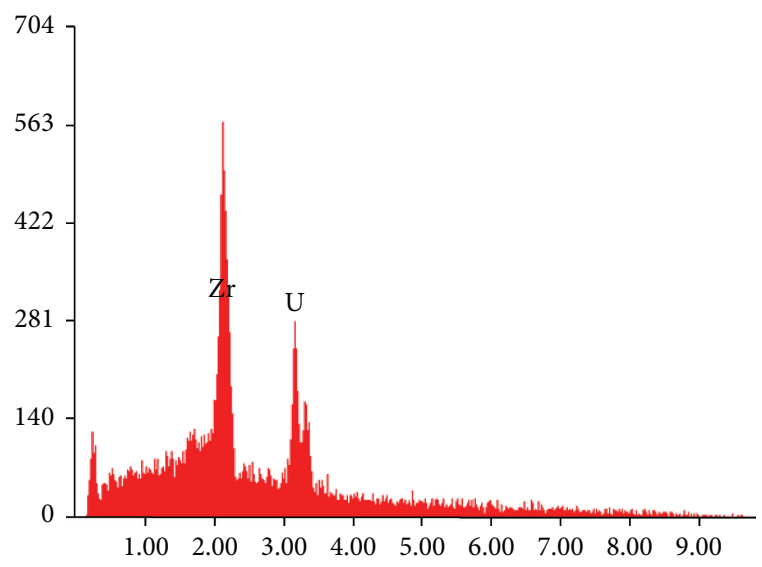

(b)

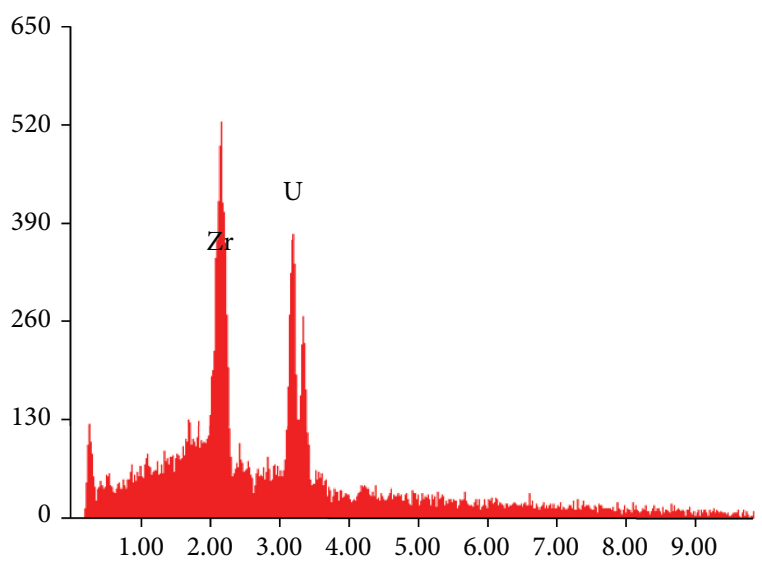

(c)

FIgURE 5: (a) Magnified micrograph of sample E (-325 mesh) sintered at $1100^{\circ} \mathrm{C}$ for $1 \mathrm{~h}$ and EDX spectra at the inclusion existing (b) within the particle and (c) at the interface of the particles.

samples C (70-100 mesh) and E (-325 mesh) are shown in Figure 4. Slender sintering necks began to form between the particles in sample E. However, sample C shows the original sphere structure without necking or bonding. A higher-magnification image of sample E (Figure 5(a)) shows some inclusions within the particles and at the interface of the particles, as indicated by the arrows in Figure 5(a). These inclusions were found to be rich in $\mathrm{Zr}$ (Figures 5(b) and 5(c)).
In order to increase the degree of sintering, the particle samples were sintered at higher temperatures and the sintering time was extended. The effect of temperature and sintering time on the density can be explained by the following equation [20]:

$$
F_{s}=F_{I}+B_{0} \exp \left(-\frac{Q}{k T}\right) \ln (t)
$$




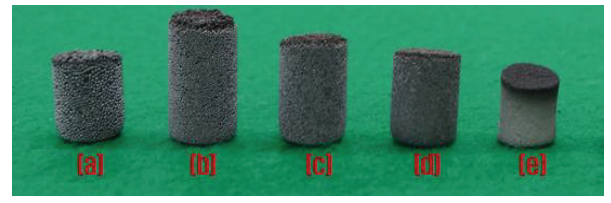

Figure 6: Photographs of bulk samples sintered at $1150^{\circ} \mathrm{C}$ for $80 \mathrm{~min}$ : (a) sample A (+50 mesh), (b) sample B (50 70 mesh), (c) sample C (70 100 mesh), (d) sample D (100 170 mesh), and (e) sample E (-325 mesh).

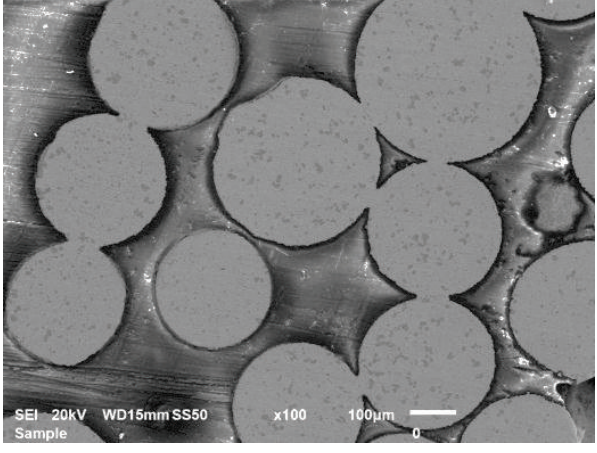

(a)

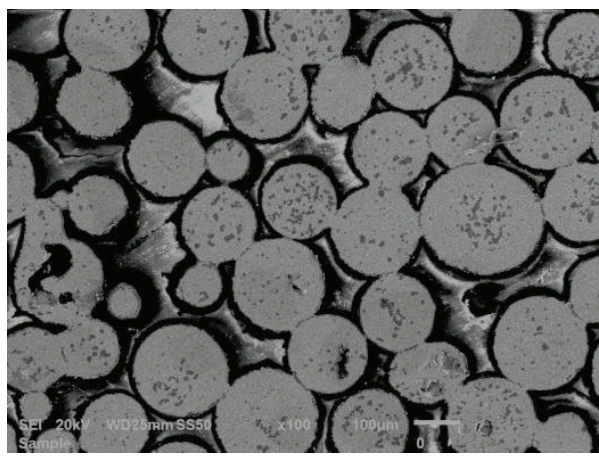

(c)

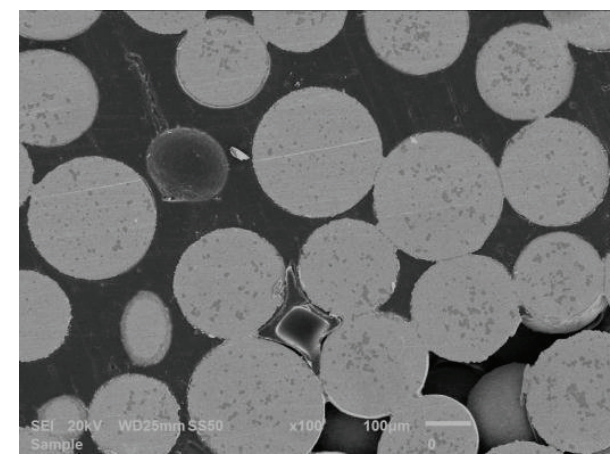

(b)

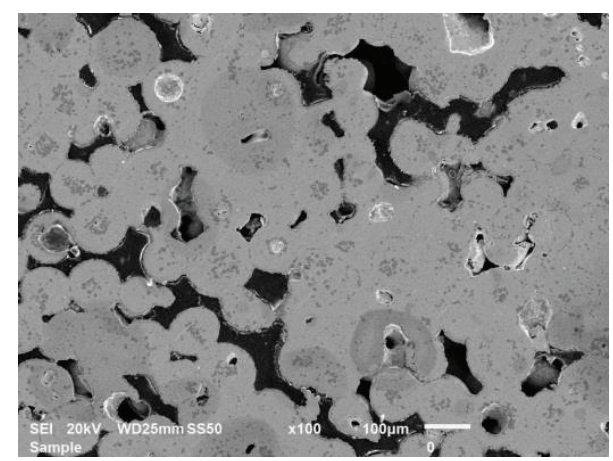

(d)

Figure 7: Scanning electron micrographs of the samples sintered at $1150^{\circ} \mathrm{C}$ for $80 \mathrm{~min}$ : (a) sample A ( $+50 \mathrm{mesh}$ ), (b) sample B (50 70 mesh), (c) sample C (70 100 mesh), and (d) sample D (100 170 mesh).

where $F_{s}$ is the sintered fractional density, $F_{I}$ is the fractional density at the beginning of the second sintering stage, $k$ is Boltzmann's constant, $T$ is the absolute temperature, $B_{0}$ is a collection of constants that depend on surface energies, atomic size, atomic vibration frequencies, and system geometry, and $t$ is the time. Because the temperature is given as an exponential term, small temperature changes can have a large effect, whereas the effect of time is relatively small.

Figure 6 shows bulk samples sintered at $1150^{\circ} \mathrm{C}$ for $80 \mathrm{~min}$. No cracks were found in any of the samples. The geometries of the sintered bodies retained the shape of the original packing state except for sample E, which shows variations in diameter, leading to an apex-truncated coneshaped body. Figure 7 shows scanning electron micrographs of these samples, which were cross-sectioned for examination. It can be seen that sintering progressed further as compared to the previous results. Samples A (+50 mesh), B (50-70 mesh), and C (70-100 mesh) show the typical initial stage of sintering, where a slender sintering neck begins to form between particles and a number of necks are observed. The pores are open and interconnected. However, sample D (100-170 mesh) shows many interconnected particles (Figure $7(\mathrm{~d})$ ), signifying that the densification went beyond necking. Instead, it entered into an intermediate stage or made a transition from an intermediate stage to the final stage. The contact interface between some particles broke because of tensile and pressure forces among the particles, and some particles formed new contacts. As the sintering progressed, it can be observed that the coordination number increased by closing pores.

Sample E with -325 mesh particles and sample $F$ with mixed particles (+50 mesh and -325 mesh) show the final stage of sintering. Most of the micropores disappeared owing to the high diffusivity at the central area of the bulk samples. Figure 8 shows optical micrographs of samples $\mathrm{E}$ and $\mathrm{F}$ at the outer region of the bulk samples, where some discrete pores are observed. Therefore, it can be concluded that U-10Zr sintering was nearly finished for samples $\mathrm{E}$ and $\mathrm{F}$. Because 


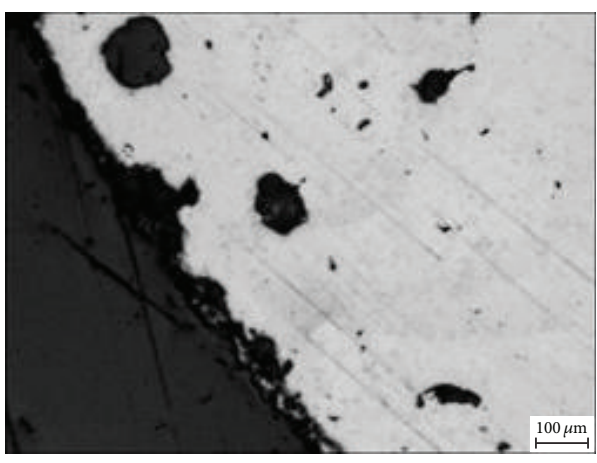

(a)

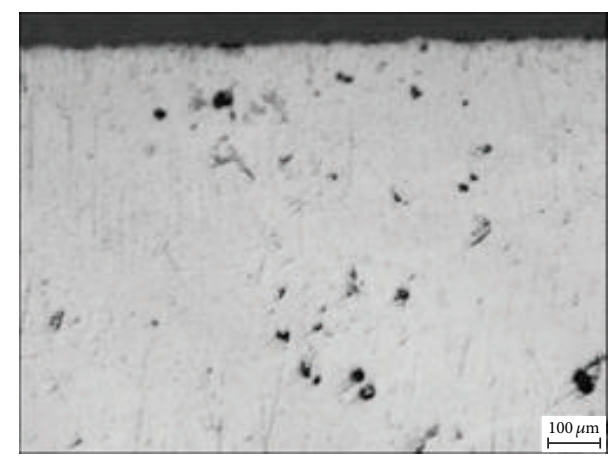

(b)

Figure 8: Optical micrographs at the outer region of (a) sample E ( -325 mesh) and (b) sample F ( +50 mesh and -325 mesh) sintered at $1150^{\circ} \mathrm{C}$ for $80 \mathrm{~min}$.

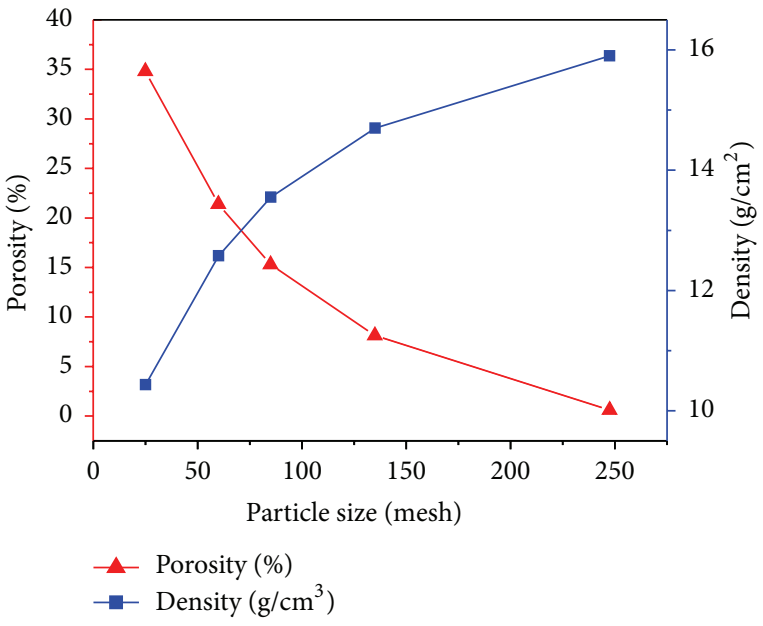

Figure 9: Porosities and densities of the bulk U-10wt\%Zr alloy prepared through pressureless sintering at $1150^{\circ} \mathrm{C}$ for $80 \mathrm{~min}$ as a function of particle size.

of the low volume and grain boundary diffusion rates, it is known that densification of particles under pressureless sintering conditions requires high temperatures and long sintering times $[15,21,22]$. However, the results for sample F, which contained mixed particles, suggest that the sinterability of U-10Zr alloy particles can be improved by the addition of small particles, without the need to control sintering variables such as temperature and sintering time.

The porosities and densities of the bulk samples are shown in Figure 9. It can be seen that the density increases as the sintered particle size decreases. The density of $\mathrm{U}$ $10 \mathrm{Zr}$ increases from $10.4 \mathrm{~g} / \mathrm{cm}^{3}$ for the sample with +50 mesh particles to $15.9 \mathrm{~g} / \mathrm{cm}^{3}$ for the sample with -325 mesh particles. On the other hand, the porosity decreases from $34.8 \%$ for the sample with +50 mesh particles to $0.6 \%$ for the sample with -325 mesh particles. This indicates that small particles promote the densification of U-10Zr particles. The sample with mixed particles also showed increased density $\left(15.5 \mathrm{~g} / \mathrm{cm}^{3}\right)$ and lower porosity (3.1\%).
For particulate fuel, interconnected pores or pore structures are important because they allow fission products developed during irradiation to travel easily to the plenum. The swelling-induced fuel-cladding mechanical interaction (FCMI) during irradiation is also expected to decrease because of structural accommodation of the volume increase. The proper porosity level therefore mainly depends on the degree of fission products and FCMI during irradiation. According to [11, 17], the porosity of particulate fuel is in the range of $14-30 \%$. Therefore, it can be said that samples B (5070 mesh) and C (70-100 mesh) have suitable pore characteristics, that is, porosities of $21.4 \%$ and $15.3 \%$, respectively, making them useful as particulate fuel.

\section{Conclusions}

From this study, it was shown that a U-10wt\%Zr particulate fuel can be fabricated through pressureless sintering, which is one of the simplest powder processing techniques. U-10Zr spherical particles were prepared by centrifugal atomization developed at the KAERI, and the pressureless sintering behavior was investigated. The prepared U-10Zr raw particles showed smooth surfaces and a near-perfect spherical shape. At sintering temperatures of $1100^{\circ} \mathrm{C}$ for $30 \mathrm{~min}$ and $1100^{\circ} \mathrm{C}$ for $60 \mathrm{~min}$, all samples ranging from +50 mesh to -325 mesh showed no apparent bonding between the particles. However, at a sintering temperature of $1150^{\circ} \mathrm{C}$ for $80 \mathrm{~min}$, all samples were densified to form bulk bodies, and the microstructures showed apparent sintering stages. Particularly, sample B (5070 mesh) and sample C (70-100 mesh) showed porosities in the range of $15-30 \%$, which are suitable for a particulate fuel. The results of mixed particles suggested that the sinterability for U-10Zr particulate fuel can be improved by the addition of small particles, without needing to control sintering variables such as temperature and sintering time.

\section{Competing Interests}

The authors declare that there are no competing interests regarding the publication of this paper. 


\section{Acknowledgments}

This study was supported by Nuclear Research \& Development Program of the National Research Foundation Grant funded by the Ministry of Education, Science and Technology in Korea (Grant no. 2013M2A8A2000676).

\section{References}

[1] Generation IV International Forum, A Technology Roadmap for Generation IV Nuclear Energy Systems, 2002.

[2] IAEA and OECD, Uranium 2007: Resources, Production and Demand, 2008.

[3] T. Abram and S. Ion, "Generation-IV nuclear power: a review of the state of the science," Energy Policy, vol. 36, no. 12, pp. 43234330, 2008.

[4] G. L. Hofman and L. C. Walters, "Metallic fast reactor fuels," Materials Science and Technology A, vol. 10, pp. 1-43, 1994.

[5] A. Riyas and P. Mohanakrishnan, "Studies on physics parameters of metal (U-Pu-Zr) fuelled FBR cores," Annals of Nuclear Energy, vol. 35, no. 1, pp. 87-92, 2008.

[6] J. H. Kittel, B. R. T. Frost, J. P. Mustelier, K. Q. Bagley, G. C. Crittenden, and J. Van Dievoet, "History of fast reactor fuel development," Journal of Nuclear Materials, vol. 204, pp. 1-13, 1993.

[7] D. C. Crawford, D. L. Porter, S. L. Hayes, M. K. Meyer, D. A. Petti, and K. Pasamehmetoglu, "An approach to fuel development and qualification," Journal of Nuclear Materials, vol. 371, no. 1-3, pp. 232-242, 2007.

[8] M. V. Nevitt, "Fast reactor fuel alloys: retrospective and prospective views," Journal of Nuclear Materials, vol. 165, no. 1, pp. 1-8, 1989.

[9] D. C. Crawford, D. L. Porter, and S. L. Hayes, "Fuels for sodium-cooled fast reactors: US perspective," Journal of Nuclear Materials, vol. 371, no. 1-3, pp. 202-231, 2007.

[10] International Atomic Energy Agency, "Development status of metallic, dispersion and non-oxide advanced and alternative fuels for power and research reactors," IAEA-TECDOC-1374, 2003.

[11] M. A. Pouchon, G. Ledergerber, F. Ingold, and K. Bakker, "Sphere-pac and vipac fuel," Comprehensive Nuclear Materials, vol. 3, pp. 275-312, 2012.

[12] G. Ledergerber, F. Ingold, R. W. Stratton et al., "Preparation of transuranium fuel and target materials for the transmutation of actinides by gel coconversion," Nuclear Technology, vol. 114, no. 2, pp. 194-203, 1996.

[13] M. Nakamura, N. Sekine, M. A. Pouchon, H. Miyamoto, and Y. Nakajima, "Development of vibro-packed fuel design code," Tech. Rep. 5, 2002, http://jolisfukyu.tokai-sc.jaea.go.jp/fukyu/ gihou/pdf2/n15-05.pdf.

[14] G. L. Hofman, L. C. Walters, and T. H. Bauer, "Metallic fast reactor fuels," Progress in Nuclear Energy, vol. 31, no. 1-2, pp. 83110, 1997.

[15] M. Mallik, S. Roy, K. K. Ray, and R. Mitra, "Effect of SiC content, additives and process parameters on densification and structure-property relations of pressureless sintered $\mathrm{ZrB} 2-\mathrm{SiC}$ composites," Ceramics International, vol. 39, no. 3, pp. 29152932, 2013.

[16] M. Zhu and Y. Wang, "Pressureless sintering $\mathrm{ZrB}_{2}-\mathrm{SiC}$ ceramics at low temperatures," Materials Letters, vol. 63, no. 23, pp. 20352037, 2009.
[17] G. Bart, F. B. Botta, C. W. Hoth, G. Ledergerber, R. E. Mason, and R. W. Stratton, "AC-3-irradiation test of sphere-pac and pellet (U,Pu)C fuel in the US Fast Flux Test Facility," Journal of Nuclear Materials, vol. 376, no. 1, pp. 47-59, 2008.

[18] A. K. Rai, R. Subramanian, R. N. Hajra, H. Tripathy, M. Rengachari, and S. Saibaba, "Calorimetric study of phase stability and phase transformation in $\mathrm{U}-x \mathrm{Zr}(\mathrm{x}=2,5,10 \mathrm{wt} \mathrm{pct})$ alloys," Metallurgical and Materials Transactions A, vol. 46, no. 11, pp. 4986-5001, 2015.

[19] R. M. German, Sintering Theory and Practice, John Wiley \& Sons, New York, NY, USA, 1996.

[20] R. M. German, Powder Injection Molding, MPIF, Princeton, NJ, USA, 1990.

[21] S. C. Zhang, G. E. Hilmas, and W. G. Fahrenholtz, "Mechanical properties of sintered $\mathrm{ZrB}_{2}-\mathrm{SiC}$ ceramics," Journal of the European Ceramic Society, vol. 31, no. 5, pp. 893-901, 2011.

[22] M. Zhu and Y. Wang, "Pressureless sintering $\mathrm{ZrB}_{2}-\mathrm{SiC}$ ceramics at low temperatures," Materials Letters, vol. 63, no. 23, pp. 20352037, 2009. 

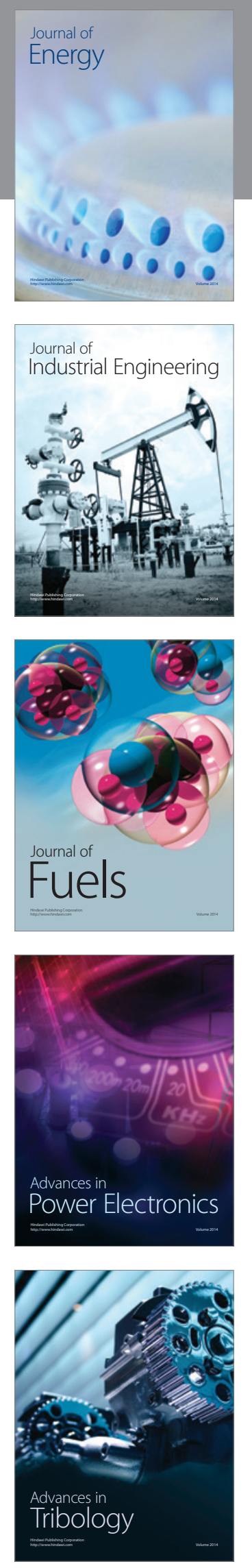
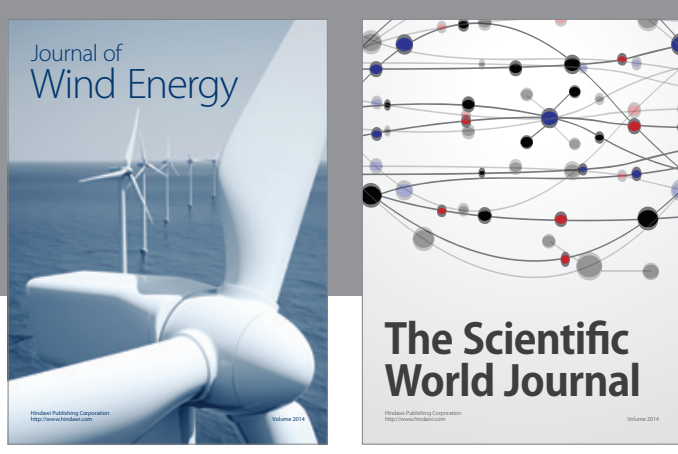

The Scientific World Journal
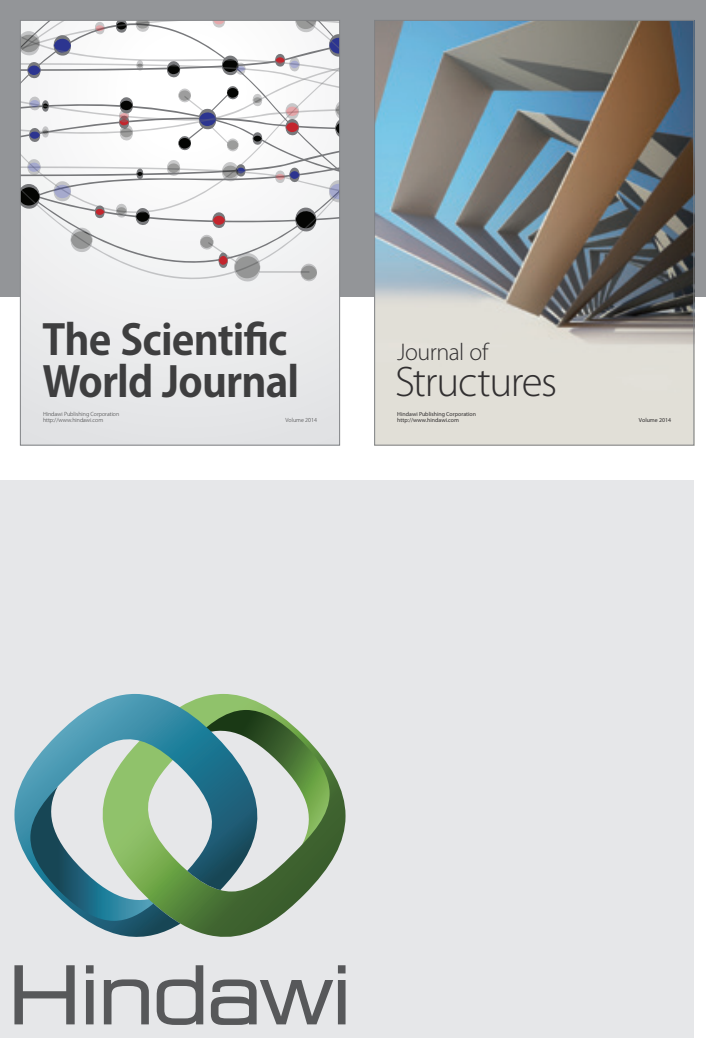

Submit your manuscripts at

http://www.hindawi.com
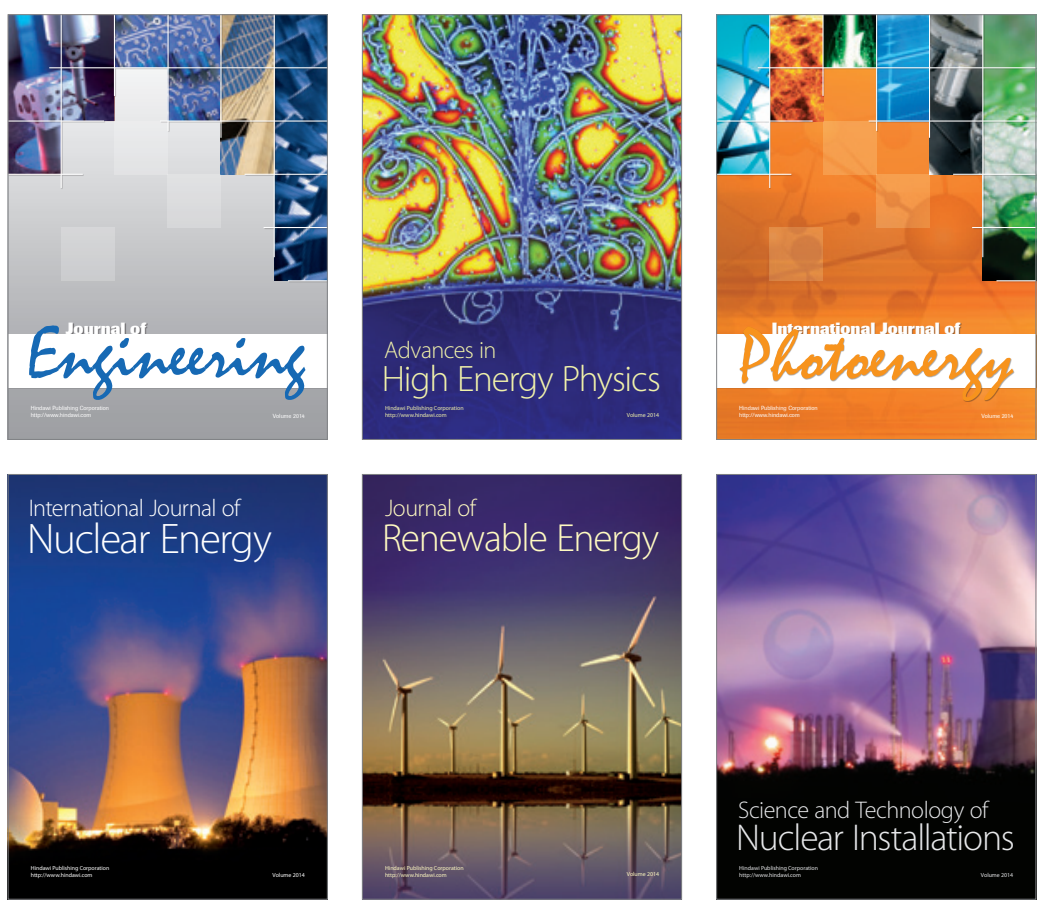
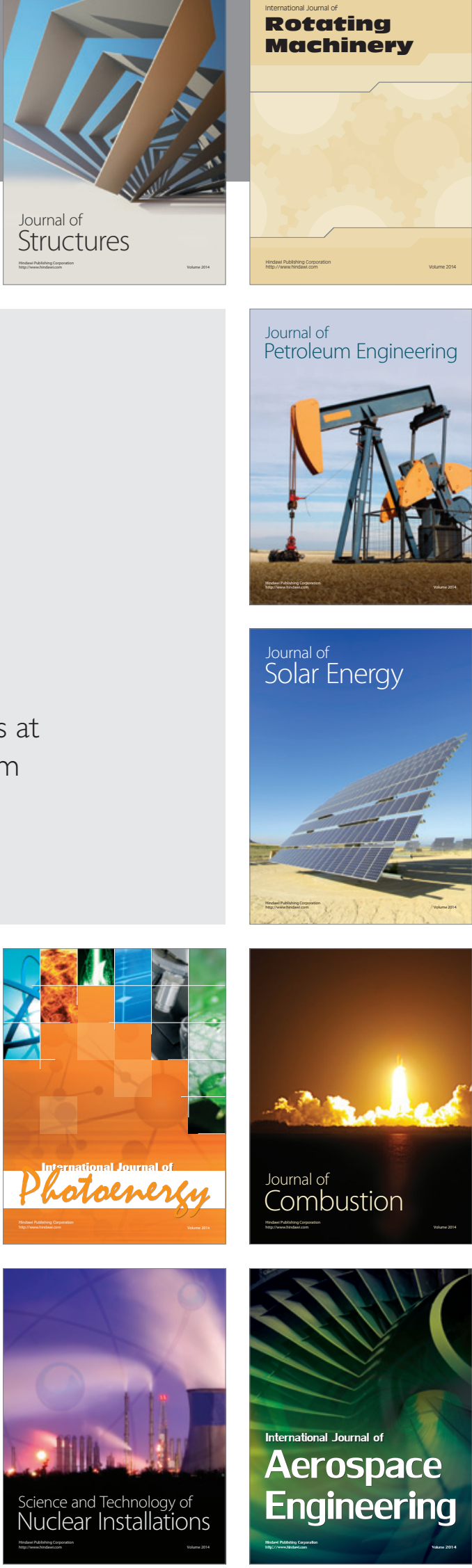